\title{
PERBANDINGAN SMA NEGERI DAN SMA SWASTA BERDASARKAN NILAI AKREDITASI DAN NILAI UJIAN NASIONAL MENGGUNAKAN UJI-T DI KOTA MANADO
}

\author{
Charles E. Mongi ${ }^{1}$, Djoni Hatidja ${ }^{1)}$ \\ ${ }^{1)}$ Program studi Matematika FMIPA UNSRAT Manado \\ e-mail: charlesmongi@unsrat.ac.id; dhatidja@yahoo.com
}

\begin{abstract}
ABSTRAK
Sekolah Menengah Atas (SMA) merupakan jenjang pendidikan menengah setelah menempuh Sekolah Menengah Pertama (SMP). SMA di kota Manado terdiri atas sekolah yang berstatus negeri dan sekolah yang berstatus swasta. Jumlah sekolah negeri di Kota Manado adalah 9 sekolah dan jumlah sekolah swasta di Kota Manado adalah 37 sekolah. Sekolah dengan status negeri lebih baik atau tidak lebih baik dengan sekolah status swasta dalam hal ini SMA di Kota Manado. Tujuan dari penelitian ini adalah membandingkan dalam rata-rata SMA dengan status negeri dan SMA dengan status swasta berdasarkan nilai UN dan Akreditasi sekolah di Kota Manado.

Data yang digunakan dalam penelitian ini adalah data nilai ujian nasional SMA di Kota Manado tahun ajaran 2014/2015 dan data nilai akreditasi SMA di Kota Manado sampai tahun 2015. Metode analisis yaitu analisis deskripsi untuk menggambarkan rata-rata sekolah berdasarkan status sekolah negeri dan swasta. Uji-t dilakukan untuk membedakan antara sekolah dengan status negeri dan sekolah dengan status swasta. Langkah-langkahnya adalah dengan membuat pengujian hipotesis statistika. Hasil dari penelitian ini diharapkan dapat memperkaya referensi tentang penerapan ilmu statistika dalam masyarakat khususnya dalam bidang pendidikan di daerah Sulawesi Utara.

Hasil yang didapat yaitu nilai t-hitung sebesar 1.28 dan nilai p sebesar 0.219 , untuk perhitungan berdasarkan nilai UN. Sedangkan untuk perhitungan berdasarkan nilai akreditasi, t-hitung sebesar 1.44 dan nilai p sebesar 0.169. Hal ini menunjukkan bahwa tidak ada perbedaan antara sekolah negeri dan sekolah swasta berdasarkan rata-rata nilai UN dan akreditasi di Kota Manado.
\end{abstract}

Kata kunci: Akreditasi, Sekolah Menengah Atas, Ujian Nasional, Uji-t

\section{PUBLIC AND PRIVATE SENIOR HIGH SCHOOL COMPARATIVE BASED ON ACCREDITATION VALUE AND NATIONAL EXAMINATION TEST USING T-TEST IN MANADO}

\begin{abstract}
Senior High School is an educational level after a Junior High School. High School in Manado consists of public school and private school, with the number of 9 public schools and private schools amounted to 37. Public schools in Manado can be better or no better than private schools. The purpose of this study is to compare the average value of National Examination and the average value of accreditation of senior high schools from public schools and private schools of Manado. The data used in this study is the national exam scores from high school in the city of Manado in the academic year 2014/2015 and the value of accreditation School in Manado until 2015. The analytical method used is the analysis of description to describe the average school based on the status of public and private schools. T-test is done to distinguish between schools with public schools and private schools, after it made a statistical hypothesis testing. The results of this study are expected to make reference to the application of statistical science in society, especially in the field of education in North Sulawesi. In calculations based on the National Examination, obtained the t-test of 1.28, and $\mathrm{p}$ value of 0219 . while the calculation based on the value of accreditation, obtained $t$ count by 1.44 and $p$ value of 0.169 . Based on that can be concluded that there is no difference between public schools and private schools based on the average of the National Examination and value of accreditation in Manado.
\end{abstract}

Keywords: Accreditation, Senior High School, National Examination, t-test. 


\section{PENDAHULUAN}

Sekolah Menengah Atas (SMA) merupakan jenjang pendidikan menengah setelah menempuh Sekolah Menengah Pertama (SMP). Di Indonesia secara formal terdapat tiga jenjang pendidikan yaitu pendidikan dasar, pendidikan menengah dan pendidikan tinggi. SMA dapat ditempuh selama 3 tahun yaitu kelas X, kelas XI dan Kelas XII masing-masing kelas satu tahun. Di akhir tahun ketiga akan dilaksanakan ujian secara nasional untuk menilai siswa dan sekolah secara bersama dalam tingkat nasional. Ujian tersebut dinamakan dengan nama Ujian Nasional (UN).

UN dilaksanakan pada jenjang pendidikan dasar dan menengah. UN SMA jenis mata pelajarannya berbeda-beda sesuai dengan program yang dipilih oleh siswa. Mata pelajaran yang diujiankan untuk program IPA yaitu Bahasa Indonesia, Bahasa Inggris, Matematika, Kimia, Biologi dan Fisika, untuk program IPS yaitu Bahasa Indonesia, Bahasa Inggris, Matematika, Ekonomi, Sosiologi dan Geografi, untuk program Bahasa yaitu Bahasa Indonesia, Bahasa Inggris, Matematika, Sastra Indonesia, Antropologi dan Bahasa asing (Bahasa Arab, Jepang, Jerman, Prancis, Mandarin) sesuai dengan pilihan (BNSP 2015).

Nilai UN melihat dari segi kualitas lulusan sedang akreditasi melihat dari segi manajemen sekolah. Akreditasi dilaksanakan oleh badan akreditasi nasional sekolah dan madrasah (BAN S-M) melalui Badan Akreditasi Provinsi (BAP). Akreditasi merupakan penilaian dalam segi manajemen suatu sekolah. Penilaian akreditasi meliputi 8 standar berdasarkan Badan Standar Nasional Pendidikan (BSNP). Kedelapan standar tersebut adalah standar isi, standar proses, standar kompetensi lulusan, standar tenaga pendidik dan kependidikan, standar sarana dan prasarana, standar pengelolaan, standar pembiayaan dan standar penilaian.

SMA di kota Manado terdiri atas sekolah yang berstatus negeri dan sekolah yang berstatus swasta. Jumlah sekolah negeri di Kota Manado adalah 9 sekolah dan jumlah sekolah swasta di Kota Manado adalah 37 sekolah (BPS Manado 2014). Penelitian sebelumnya yang dilakukan Purwanto, dkk (2015) dan Sepang, dkk (2015) yaitu Pemetaan SMA di Kabupaten Minahasa
Tenggara berdasarkan nilai 8 standar nasional pendidikan. Mongi (2014) melakukan pemetaan SMA berdasarkan nilai UN dan Akreditasi sekolah di Provinsi Jawa Barat.

Perumusan masalah dalam penelitian ini adalah apakah sekolah dengan status negeri sama atau berbeda dengan sekolah dengan status swasta. Sekolah dengan status negeri lebih baik atau tidak lebih baik dengan sekolah status swasta dalam hal ini SMA di Kota Manado. Tujuan dari penelitian ini adalah membandingkan dalam rata-rata SMA dengan status negeri dan SMA dengan status swasta berdasarkan nilai UN dan Akreditasi sekolah di Kota Manado.

\section{Tujuan Penelitian}

Tujuan dari penelitian ini adalah membandingkan dalam rata-rata SMA dengan status negeri dan SMA dengan status swasta berdasarkan nilai Ujian Nasional dan Akreditasi sekolah di Kota Manado.

\section{TINJAUAN PUSTAKA \\ Kota Manado}

Manado terletak di Provinsi Sulawesi Utara, berbatasan langsung dengan Kabupaten Minahasa dan Minahasa Utara sedangkan di barat berbatasan dengan Laut Sulawesi. Kota Manado terletak antara $1^{\circ} 30^{\prime}-1^{\circ} 40^{\prime}$ Lintang Utara dan antara $124^{\circ} 40^{\prime}-126^{\circ} 50^{\prime}$ Bujur Timur. Luas wilayah Manado sebesar 157,26 Km2 (BPS 2015).

Banyaknya sekolah di Kota Manado adalah TK 141 sekolah, SD 261 sekolah, SMP 85 sekolah dan SMA 46 sekolah. SMA di Kota Manado terdiri dari 9 sekolah dengan status negeri dan 37 sekolah dengan status swasta. Dengan rasio murid terhadap guru adalah 1:15. Jumlah lulusan SMA pada tahun 2011 adalah 2357 untuk sekolah negeri dan 1364 untuk sekolah swasta.

\section{Pengujian Hipotesis}

Suatu hipotesis statistika adalah pernyataan atau dugaan mengenai satu atau lebih populasi, kebenaran atau kesalahan dari hipotesis statistika tidak dapat diketahui secara pasti sampai pada pengujian seluruh populasi. Struktur pengujian hipotesis dirumuskan dengan penggunaan istilah hipotesis nol yang dilambangkan dengan $\mathrm{H}_{0}$ dan hipotesis alternatif dilambangkan dengan $\mathrm{H}_{1}$. Hipotesis alternatif biasanya 
merepresentasikan pertanyaan yang harus dijawab atau teori yang akan diuji. $\mathrm{H}_{1}$ merupakan lawan dari $\mathrm{H}_{0}$. Menolak $\mathrm{H}_{0}$ karena cukup bukti dari data atau gagal menolak $\mathrm{H}_{0}$ karena tidak cukup bukti dari data (Walpole et al 2012).

Pengujian hipotesis adalah prosedur perumusan kaidah yang membawa kita pada penerimaan atau penolakan hipotesis. Benar tidaknya suatu hipotesis tidak akan pernah kita ketahui dengan pasti, kecuali bila kita memeriksa seluruh populasi. Salah satu proses yang akan kita tempuh dalam pengujian hipotesis adalah pengambilan keputusan atau kesimpulan. Data yang kita gunakan dalam membuat kesimpulan berasal dari contoh/sampel, namun kesimpulan yang diambil menyangkut keadaan keseluruhan dari populasi. Oleh karena itu, dalam mengambil kesimpulan kita tidak akan lepas dari kesalahan (error). Namun harus diusahakan agar kesalahan tersebut sekecil mungkin.

Kesalahan yang kita buat dalam mengambil kesimpulan terdiri dari dua jenis, yaitu: salah jenis I $(\alpha)$, dan salah jenis II $(\beta)$. Salah jenis I $(\alpha)$ adalah kesimpulan yang terjadi akibat $\mathrm{H}_{0}$ yang ditolak sesungguhnya benar. Sedangkan salah jenis II $(\beta)$ adalah kesalahan yang terjadi akibat menerima $\mathrm{H}_{0}$ yang sesungguhnya salah. Kedua jenis kesalahan tersebut dapat dibuat seperti table 1 (Hatidja 2009):

Tabel 1. Keputusan dalam pengambilan kesimpulan

\begin{tabular}{|c|c|c|c|}
\hline & & \multicolumn{2}{|c|}{ Keadaan Sesungguhnya } \\
\hline \multirow{4}{*}{ Kesimpulan } & & Hon $_{\mathbf{0}}$ Benar & H$_{\mathbf{1}}$ Benar \\
\cline { 2 - 4 } & Terima $\mathbf{H}_{\mathbf{0}}$ & Keputusan benar & salah jenis II $(\beta)$ \\
\cline { 2 - 4 } & Tolak $\mathbf{H}_{\mathbf{0}}$ & salah jenis I $(\alpha)$ & Keputusan benar \\
\hline
\end{tabular}

Langkah-langkah dalam menguji hipotesis bagi selisih rata-rata dua populasi saling bebas, yaitu :

1. Menetapkan hipotesisnya
a). $H_{0}: \mu_{1}-\mu_{2} \geq \delta$
b). $H_{0}: \mu_{1}-\mu_{2} \leq \delta$
c). $H_{0}: \mu_{1}-\mu_{2}=\delta$
$\mathrm{H}_{1}: \mu_{1}-\mu_{2}<\delta$
$\mathrm{H}_{1}: \mu_{1}-\mu_{2}>\delta$
$\mathrm{H}_{1}: \mu_{1}-\mu_{2} \neq \delta$

2. Tentukan $\alpha$

3. dan 4. untuk menentukan statistic uji ada 3 kondisi yang harus dilihat, yaitu :

I. Bila simpangan baku dari populasi I dan II $\left(\sigma_{1}\right.$ dan $\left.\sigma_{2}\right)$ diketahui, maka digunakan uji-Z :

$$
Z_{\text {hit }}=\frac{\left(\bar{x}_{1}-\bar{x}_{2}\right)-\delta}{\sqrt{\frac{\delta_{1}^{2}}{n_{1}}+\frac{\delta_{2}^{2}}{n_{2}}}}
$$

II. Bila simpangan baku dari populasi I dan II $\left(\sigma_{1}\right.$ dan $\left.\sigma_{2}\right)$ tidak diketahui dan $\left(\mathrm{n}_{1}+\mathrm{n}_{2}\right) \geq 30$, maka gunakan uji-Z :

$$
\begin{aligned}
& \sigma_{1} \cong s_{1} ; \sigma_{2} \triangleq s_{2} \\
& Z_{h i t}=\frac{\left(\bar{x}_{1}-\bar{x}_{2}\right)-\delta}{\sqrt{\frac{s_{1}^{2}}{n_{1}}+\frac{s_{2}^{2}}{n_{2}}}}
\end{aligned}
$$

III. Bila simpangan baku dari populasi I dan II $\left(\begin{array}{lll}\sigma_{1} & \text { dan } & \sigma_{2}\end{array}\right)$ tidak diketahui namun $\sigma_{1}=\sigma_{2}$; dan $\left(\mathrm{n}_{1}+\mathrm{n}_{2}-2\right)<30$, maka gunakan uji-t :

$$
\begin{array}{r}
\sigma_{1}=s_{1} ; \sigma_{2} \hat{=} s_{2} \\
t_{h i t}=\frac{\left(\bar{x}_{1}-\bar{x}_{2}\right)-\delta}{s_{p} \sqrt{\frac{1}{n_{1}}+\frac{1}{n_{2}}}} \\
s_{p}^{2}=\frac{\left(n_{1}-1\right) s_{1}^{2}+\left(n_{2}-1\right) s_{2}^{2}}{n_{1}+n_{2}-2}
\end{array}
$$

IV. Bila simpangan baku dari populasi I dan II $\left(\sigma_{1}\right.$ dan $\left.\sigma_{2}\right)$ tidak diketahui namun $\sigma_{1} \neq \sigma_{2}$; dan $\left(\mathrm{n}_{1}+\mathrm{n}_{2}-2\right)<30$, maka gunakan uji-t :

$$
\begin{aligned}
\sigma_{1} & =s_{1} ; \sigma_{2} \subseteq s_{2} \\
t_{h i t} & =\frac{\left(\bar{x}_{1}-\bar{x}_{2}\right)-\delta}{\sqrt{\frac{s_{1}^{2}}{n_{1}}+\frac{s_{2}^{2}}{n_{2}}}, \text { dengan }} \\
\text { derajat bebas } v & =\frac{\left(\left(s_{1}^{2} / n_{1}\right)+\left(s_{2}^{2} / n_{2}\right)\right)^{2}}{\frac{\left(s_{1}^{2} / n_{1}\right)^{2}}{n_{1}-1}+\frac{\left(s_{2}^{2} / n_{2}\right)^{2}}{n_{2}-1}}
\end{aligned}
$$

5. Lihat nilai tabel. Tabel yang digunakan adalah tabel-Z dan tabel-t. 
untuk hipotesis model (a) atau (b) : $\mathrm{Z}_{\text {tabel }}=\mathrm{Z}_{\alpha} ; \quad \mathrm{t}_{\text {tabel }}=\mathrm{t}_{\alpha}(\mathrm{v}) ; \quad \mathrm{v}=(\mathrm{n}-1)$ untuk hipotesis model (c) : $\mathrm{Z}_{\text {tabel }}=\mathrm{Z}_{\alpha / 2}$ $; \mathrm{t}_{\text {tabel }}=\mathrm{t}_{\alpha / 2}(\mathrm{v}) ; \mathrm{v}=(\mathrm{n}-1)$

6. Kesimpulan.

* untuk hipotesis (a), cara membuat kesimpulannya adalah : bila $\mathrm{Z}_{\text {hit }}<-\mathrm{Z}_{\text {tabel }}$, maka tolak $\mathrm{H}_{0}$ bila $\mathrm{t}_{\text {hit }}<-\mathrm{t}_{\text {tabel }}$, maka tolak $\mathrm{H}_{0}$

* untuk hipotesis model (b), cara membuat kesimpulannya adalah : bila $\mathrm{Z}_{\text {hit }}>\mathrm{Z}_{\text {tabel }}$, maka tolak $\mathrm{H}_{0}$ bila $\mathrm{t}_{\text {hit }}>\mathrm{t}_{\text {tabel }}$, maka tolak $\mathrm{H}_{0}$

* untuk hipotesis model (c), cara membuat kesimpulannya adalah : bila $\left|Z_{\text {hit }}\right|>\mathrm{Z}_{\text {tabel }}$, maka tolak $\mathrm{H}_{0}$ bila $\left|t_{\text {hit }}\right|>\mathrm{t}_{\text {tabel }}$, maka tolak $\mathrm{H}_{0}$

\section{METODE}

1. Sumber Data

Data yang digunakan dalam penelitian ini adalah:

a. Data nilai ujian nasional SMA di Kota Manado tahun ajaran 2014/2015. Data tersebut merupakan data rata-rata setiap sekolah. Data nilai ujian nasional diambil pada laman kementerian pendidikan dan kebudayaan.

b. Data nilai akreditasi SMA di Kota Manado sampai tahun 2015. Data tersebut merupakan nilai rata-rata dari kedelapan standar dengan skala nilai 0-100. Data nilai akreditasi akan dibuat kedalam peringkat akreditasi berupa nilai huruf A, B, atau C. Data nilai akreditasi diambil pada laman badan akreditasi sekolah dan madrasah.

Data sekolah yang akan dipakai berasal dari semua sekolah negeri yaitu 9 sekolah dan sekolah swasta menyesuaikan dengan jumlah sekolah negeri yaitu 9 sekolah. Jumlah sekolah swasta akan dipilih 9 dari 37 SMA swasta di Kota Manado berdasarkan sekolah dengan jumlah siswa terbanyak dan ada tidaknya data akreditasi sekolah tersebut.

2. Metode Analisis

a. Analisis deskripsi

Analisis deskripsi untuk menggambarkan rata-rata sekolah berdasarkan status sekolah negeri dan swasta. Analisis deskripsi berupa tabel rata-rata sekolah berdasarkan status sekolah dan boxplot sekolah berdasarkan status sekolah.

b. Uji-t

Uji-t dilakukan untuk membedakan antara sekolah dengan status negeri dan sekolah dengan status swasta. Langkah-langkahnya adalah dengan membuat pengujian hipotesis statistika. Hipotesis statistika yang akan dibuat yaitu, apakah rata-rata nilai sekolah negeri berbeda dengan rata-rata nilai sekolah swasta?

Langkah-langkah pengujian hipotesis statistika adalah sebagai berikut:

- Membuat hipotesis

$$
\text { 1. } \mathrm{H}_{0}: \mu_{1}-\mu_{2}=0
$$$$
\mathrm{H}_{1}: \mu_{1}-\mu_{2} \neq 0
$$

- Menentukan taraf nyata atau $\alpha$. Nilai $\alpha$ yang digunakan adalah $5 \%$.

- Menetapkan statistik uji. Uji yang digunakan yaitu uji-t

- Menghitung nilai statistik uji yaitu:

$$
t_{\text {hit }}=\frac{\left(\bar{x}_{1}-\bar{x}_{2}\right)-\delta}{\sqrt{\frac{s_{1}^{2}}{n_{1}}+\frac{s_{2}^{2}}{n_{2}}}}, \quad \text { dengan }
$$

derajat bebas

$$
v=\frac{\left(\left(s_{1}^{2} / n_{1}\right)+\left(s_{2}^{2} / n_{2}\right)\right)^{2}}{\frac{\left(s_{1}^{2} / n_{1}\right)^{2}}{n_{1}-1}+\frac{\left(s_{2}^{2} / n_{2}\right)^{2}}{n_{2}-1}}
$$

- Menentukan nilai tabel. Tabel yang digunakan adalah tabel-t.

$$
\mathrm{t}_{\text {tabel }}=\mathrm{t}_{\alpha / 2}(\mathrm{v}) ; \mathrm{v}=(\mathrm{n}-1)
$$

- Membuat kesimpulan

Cara membuat kesimpulannya adalah:

bila $\left|t_{\text {hit }}\right|>t_{\text {tabel }}$, maka tolak $\mathrm{H}_{0}$

\section{HASIL DAN PEMBAHASAN}

Nilai UN adalah rata-rata dari mata ujian setiap sekolah khusus program IPS serta IPA, hasilnya seperti dalam Tabel 2. Sekolah negeri yang digunakan adalah semua SMA negeri di Kota Manado sedangkan sekolah swasta yang diambil yaitu SMA yang memiliki jumlah siswa yang banyak dan telah 
memiliki nilai akreditasi. SMA negeri yang memiliki nilai UN tertinggi adalah SMA negeri 1 diikuti oleh SMA negeri 9 dan SMA negeri 2 sedangkan nilai UN terendah adalah SMA negeri 10. Nilai UN tertinggi untuk sekolah swasta adalah SMA Rex Mundi dan nilai terendah yaitu SMA Pertiwi.
Nilai akreditasi merupakan skor dari 0 sampai 100 dan merupakan perhitungan dari 8 komponen standar nasional pendidikan. Nilai akreditasi tertinggi untuk sekolah negeri adalah SMA negeri 2 dan terendah SMA negeri 10 sedangkan untuk sekolah swasta SMA Eben Haezer memperoleh nilai tertinggi dan SMA El Fatah dengan nilai terendah.

Tabel 2. Nilai ujian nasional dan nilai akreditasi sekolah negeri dan sekolah swasta

\begin{tabular}{|l|c|c|l|c|c|}
\hline $\begin{array}{c}\text { Sekolah } \\
\text { Negeri }\end{array}$ & Nilai UN & $\begin{array}{c}\text { Nilai } \\
\text { Akreditasi }\end{array}$ & \multicolumn{1}{|c|}{ Sekolah Swasta } & Nilai UN & $\begin{array}{c}\text { Nilai } \\
\text { Akreditasi }\end{array}$ \\
\hline SMA 1 & 74.76 & 90 & SMA Rex Mundi & 74.52 & 88 \\
\hline SMA 2 & 73.45 & 93 & SMA Eben Haezer & 66.00 & 96 \\
\hline SMA 3 & 69.45 & 90 & SMA Pioneer & 63.49 & 91 \\
\hline SMA 4 & 64.59 & 92 & SMA Pertiwi & 33.07 & 78 \\
\hline SMA 6 & 58.37 & 86 & SMA Iqnatius & 57.99 & 79 \\
\hline SMA 7 & 73.33 & 90 & SMA Imam Bonjol & 43.23 & 84 \\
\hline SMA 8 & 65.14 & 90 & SMA El Fatah & 63.92 & 74 \\
\hline SMA 9 & 74.51 & 92 & SMA Muhamadiyah & 35.95 & 87 \\
\hline SMA 10 & 32.83 & 78 & SMA Irene & 70.40 & 88 \\
\hline
\end{tabular}

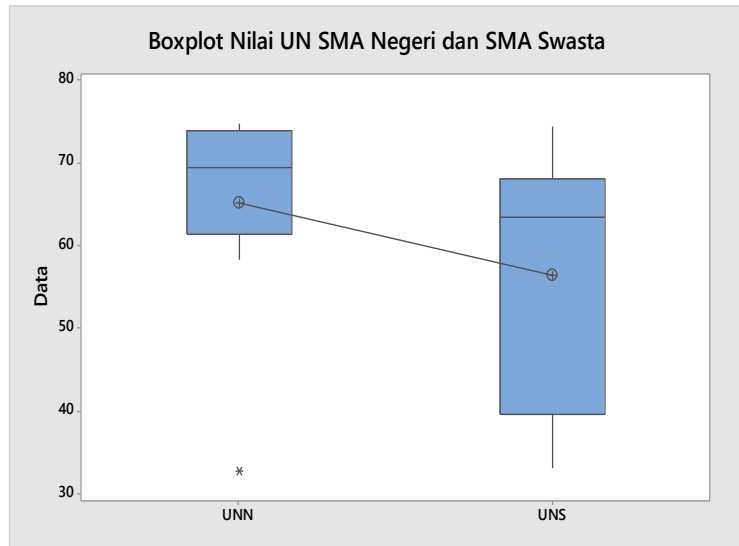

Gambar 1. Diagram kotak garis (boxplot) nilai UN SMA negeri dan SMA swasta

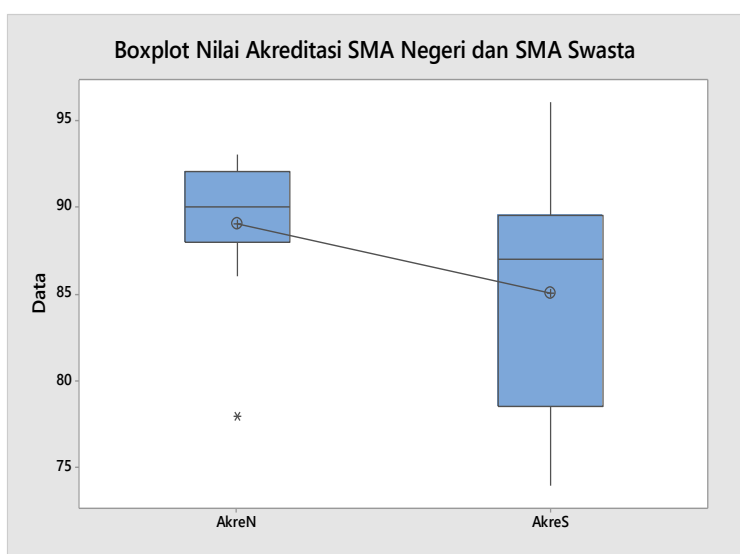

Gambar 2. Diagram kotak garis (boxplot) nilai akreditasi SMA negeri dan SMA swasta

Diagram boxplot nilai UN SMA negeri dan SMA swasta terdapat pada Gambar 1.
Nilai rata-rata UN sekolah negeri sebesar 65.16 dan nilai rata-rata UN sekolah swasta sebesar 56.51. nilai median juga menunjukkan sekolah negeri lebih besar dari sekolah swasta yaitu 69.45 dan 63.49. Penyebaran nilai sekolah swasta lebih besar dari penyebaran nilai sekolah negeri dapat dilihat dari lebarnya kotak dan garis atau ekor dari boxplot, penyebaran juga dapat diperhatikan dengan nilai jangkauan antar kuartil yang besar yaitu 28.61 dan 12.5 berturut-turut untuk sekolah swasta dan negeri. Hal menarik yang perlu diperhatikan adalah terdapat sebuah nilai pencilan bawah pada sekolah negeri.

Gambar 2 adalah diagram boxplot nilai akreditasi SMA negeri dan SMA swasta. Hal yang sama seperti pada nilai UN secara rata-rata sekolah negeri lebih besar dari sekolah swasta yaitu 89 dan 85 untuk nilai akreditasi. Nilai median juga sekolah negeri lebih besar yaitu 90 dan sekolah swasta 87 . Penyebaran nilai akreditasi sekolah swasta lebih besar dari sekolah negeri dengan memperhatikan nilai jangkauan antar kuartil berturut-turut yaitu 11 dan 4 . Pencilan juga ada pada nilai akreditasi sekolah negeri yaitu sebuah nilai pencilan bawah.

Hasil perhitungan uji-t untuk nilai UN sekolah negeri dan sekolah swasta terdapat pada Tabel 3. Nilai t-hitung sebesar 1.28 dan nilai $\mathrm{p}$ sebesar 0.219 yang lebih besar dari $\alpha$ $(\alpha=0.05)$ menunjukkan bahwa hipotesis nol 
diterima artinya rata-rata nilai UN sekolah negeri dan sekolah swasta sama. Hal ini bisa diakibatkan karena nilai simpangan baku yang cukup besar baik untuk kedua nilai UN tersebut.

Perhitungan uji-t nilai akreditasi sekolah negeri dan sekolah swasta ditampilkan dalam Tabel 4. Nilai t-hitung sebesar 1.44 dan nilai $p$ sebesar 0.169 , nilai $p$ tersebut lebih besar dari nilai $\alpha(\alpha=0.05)$ hal ini menyebabkan hipotesis nol diterima. Hipotesis nol diterima artinya bahwa rata-rata nilai akreditasi sekolah negeri dan sekolah swasta adalah sama. Seperti dalam nilai UN bahwa hipotesis nol ditolak walaupun nilai rata-rata menunjukkan perbedaan tetapi berdasarkan uji-t menunjukkan tidak ada perbedaan. Hal tersebut mungkin juga karena jumlah pengamatan yang sedikit yaitu masingmasing 9 .

Tabel 3. Hasil uji-t nilai UN sekolah negeri dan sekolah swasta

\begin{tabular}{|l|l|l|}
\hline \multicolumn{2}{|l|}{ Two-sample T for UNN vs UNS } \\
\hline \multicolumn{2}{|l|}{ N Mean StDev SE Mean } \\
\hline UNN $965.2 \quad 13.3$ & 4.4 \\
\hline UNS 956.5 & $15.3 \quad 5.1$ \\
\hline Difference $=\mu(\mathrm{UNN})-\mu(\mathrm{UNS})$ \\
\hline Estimate for difference: 8.65 \\
\hline 95\% CI for difference: $(-5.67,22.97)$ \\
\hline T-Test of difference $=0(\mathrm{vs} \neq):$ T-Value $=1.28 \quad \mathrm{P}$-Value $=0.219 \quad \mathrm{DF}=16$ \\
\hline
\end{tabular}

Tabel 4. Hasil uji-t nilai akreditasi sekolah negeri dan swasta

\begin{tabular}{|lll|}
\hline \multicolumn{2}{|c|}{ Two-sample T for AkreN vs AkreS } \\
\hline \multicolumn{2}{|c|}{ N Mean StDev SE Mean } \\
\hline AkreN 989.00 & 4.58 & 1.5 \\
\hline AkreS 985.00 & 6.95 & 2.3 \\
\hline Difference $=\mu($ AkreN) $-\mu($ AkreS $)$ \\
\hline Estimate for difference: 4.00 \\
\hline 95\% CI for difference: $(-1.88,9.88)$ \\
\hline T-Test of difference $=0($ vs $\neq):$ T-Value $=1.44$ P-Value $=0.169 \quad \mathrm{DF}=16$ \\
\hline
\end{tabular}

\section{KESIMPULAN DAN SARAN Kesimpulan}

Nilai t-hitung sebesar 1.28 dan nilai $\mathrm{p}$ sebesar 0.219 , untuk perhitungan berdasarkan nilai UN. Sedangkan untuk perhitungan berdasarkan nilai akreditasi, t-hitung sebesar 1.44 dan nilai $p$ sebesar 0.169 . Hal ini menunjukkan bahwa tidak ada perbedaan antara sekolah negeri dan sekolah swasta berdasarkan rata-rata nilai UN dan nilai akreditasi di Kota Manado.

\section{Saran}

Penelitian selanjutnya dapat dilakukan dengan menggunakan seluruh sekolah swasta di Kota Manado karena pada penelitian ini sudah menggunakan seluruh sekolah negeri. Sehingga diharapkan memberikan hasil yang dapat dibandingkan dengan penelitian yang sudah dilakukan ini.

\section{DAFTAR PUSTAKA}

BPS Manado. 2014. Manado Dalam Angka 2014. Badan Pusat Statistik Kota Manado. Manado.

BPS Manado. 2015. Statistik Kota Manado 2015. Badan Pusat Statistik Kota Manado. Manado.

BSNP. 2015. Prosedur Operasional Standar Penyelenggaraan Ujian Nasional Tahun Pelajaran 2014/2015. Badan Standar Nasional Pendidikan. Jakarta

Hatidja, D. 2009. Diktat Metode Statistika. Jurusan Matematika Fakultas MIPA UNSRAT. Manado

Mongi, CE. 2014. Pemetaan Kabupaten/Kota di Provinsi Jawa Barat Berdasarkan Nilai Ujian Nasional dan Akreditasi Sekolah. Jurnal Ilmiah Sains 14(2):146151.

Purwanto C, D. Hatidja, M. Paendong. 2015. Pemetaan SMA/SMK di Kabupaten Minahasa Tenggara Berdasarkan Empat Indikator Standar Nasional Pendidikan 
dengan Menggunakan Analisis Biplot. Jurnal de Cartesian 4(1):34-41.

Sepang M, D. Hatidja, Y. Langi. 2015. Pemetaan SMA dan SMK Berdasarkan Standar Kompetensi Lulusan, Proses, Pembiayaan Pendidikan, dan Penilaian Pendidikan Menggunakan Analisis Biplot di Kabupaten Minahasa Tenggara. Jurnal de Cartesian 4(2):210217

Walpole RE, RH Myers, SL Myers, K Ye. 2012. Probability \& Statistics for Engineers \& Scientist $9^{\text {th }} \mathrm{ed}$. Prentice Hall. Boston. 